\title{
Interrelationships Among Dependency, Empathy, and
}

\section{Sharing}

\section{A Preliminary Study}

Shirley Matile Miller

The University of Michigan

The sharing behavior of 66 fourth-grade students was observed in two different experimental situations: (a) in the experimenter's presence (visible sharing), and (b) anonymously (invisible sharing). In addition, measures of empathy and dependency were given to each child. For girls some support was found for a positive relationship between empathy and sharing in both of the experimental conditions; also, moderate dependency, as measured by peer and teacher ratings, was related to invisible sharing. The correlations found among the variables were quite different for boys. Both empathy and dependency, as measured by the Children's Social Desirability Questionnaire, were negatively related to invisible sharing, and empathy was positively correlated to social desirability scores. Also, as indicated by curvilinear analyses, the interrelationships among these variables for boys were more complex than were suggested by simple linear correlations.

Dependency, empathy, and sharing are all social constructs. Interrelationships among these three variables, rather than developmental or situational considerations, are hypothesized and tested in this study.

The child who is dependent emotionally (as defined by Heathers, 1955) upon a significant other is desirous of eliciting certain reactions from that other toward himself. Because of the salience of the reactions of the other to the dependent individual, he is constantly motivated to understand what the other person is feeling and thinking since such matters could be highly relevant to his own needs. In short, the emotionally dependent person is motivated to be empathic toward those whose regard is important to him. The individual with low dependency needs may care less about what others think and feel regarding himself, so he may have less reason to be empathic. 
The above analysis may hold true for moderate dependency needs, but it is doubtful if the person with extremely high dependency needs is empathic toward others. Rather, the intensity of his own needs may preclude the highly dependent individual's being aware of the needs of others.

The model being proposed, then, is a curvilinear relationship between dependency and empathy. Those individuals who have low dependency needs may tend to be less empathic toward others simply because others are not that necessary or important to them. Individuals with very high dependency needs are also less empathic toward others because the salience of their own needs precludes sensitivity toward others. Only the individual with moderate dependency needs will have maximum empathy toward others since this is functional to his need gratification, and his capacity is not limited by the intensity of his needs.

Both dependency and empathy may be related to a child's willingness to share with others. Hoffman (1975) hypothesized that empathy is one possible motivating factor leading to prosocial behavior, and some evidence has been found to support this (Aronfreed \& Paskal, 1965; Krebs, 1975; Martin, 1972).

If dependency and empathy are related as predicted above, then those individuals who are moderate in dependency would be most likely to share since they are hypothesized to be highest in empathy. However, in instances where a prosocial act might satisfy a dependency need, dependency would be expected to relate directly to sharing. For example, if a teacher asks each child to donate money to a fund for poor children, those children to whom the teacher's approval is most important logically could be expected to donate the most money. Such cases could be labeled visible sharing as opposed to invisible sharing when the prosocial or helping act would remain completely anonymous.

In other words, dependency should relate positively and in a linear manner to visible sharing when these prosocial acts would result in approval or affection from another. However, in the invisible sharing situation dependency is not a directly relevant motivation but is mediated by empathy. Hence, dependency would be expected to relate in a curvilinear manner to invisible sharing, with those individuals who are moderate in dependency being most generous.

\section{METHOD}

\section{Subjects}

The subjects were 66 predominantly white primarily middle-class fourth-grade children from two elementary schools in Ann Arbor, 
Michigan. Twenty-seven of the children were girls and 39 were boys. At the time they were tested, 46 of the children were 9 years of age and 20 of the children were 10 years of age.

\section{Materials}

Dependency. The primary measure of dependency was Crandall's adaptation (Crandall, Crandall, \& Katkovsky, 1965) of the MarloweCrowne Social Desirability Scale (Crowne \& Marlowe, 1964). The Children's Social Desirability Questionnaire, designed to measure need for approval, is composed of 47 questions. For the younger children (third through fifth grades) for whom the test was designed, the scale is administered individually with a direct-question format.

Questions are worded so that the socially desirable response is improbable. Sample items are: "Do you always enjoy yourself at a party?" and "Do you sometimes tell a little lie?" The socially desirable response is "yes" on 13 of the items and "no" on 34 of the items.

However, as noted by Crandall (1966), children scoring high on this scale do not actively seek approval from others, indicating that this scale may assess only those individuals with high need for approval and specific expectancies-namely, of rejection. Because of this problem with the scale and because need for approval is only one of several dependency motivations, two other dependency measures, a sociometric measure and a teacher rating scale, were included in this study.

Four different behavior descriptions, given below, were included in the sociometric measure. Peer Rating $l$ (high dependency with fears of rejection): "This person is very quiet in class. He or she often stands and watches other children play instead of joining in. Often this person likes to stand close to the teacher." Peer Rating 2 (high dependency as evidenced by negative attention seeking behaviors): "This person often talks a lot in a loud voice and wants others to watch him or her do things. Sometimes this person does things just for attention." Peer Rating 3 (moderate dependency): "This person likes to play with others and often asks them to come play with him or her. Also, this person likes to do things for the teacher." Peer Rating 4 (low dependency): "This person likes to play by himself a lot and does not ask for help in doing very hard things. This person often has hobbies that he or she is very interested in."

Two different measures of high dependency were included in the peer ratings because, as is suggested by Martin (1975) in his review of the dependency literature, two different patterns of behavior may, to some extent, be representative of dependency motivation. From previous research with the Children's Social Desirability Questionnaire (Crandall, 1966), this measure would be expected to be highly correlated with Perr Rating 1 but not with Peer Rating 2. 
The sociometric scale was administered as follows: Each child was given a list of all the children in his class. The behavioral descriptions were read by the experimenter, and after each the child was asked to choose the three people from his class who best fit that description. Each individual's score on the measure was his ranking among his classmates according to the number of peer nominations he received for each behavioral description.

The teacher rating scale was modeled after Coopersmith's (1967) rating scale. Several of the original items were modified to more specifically describe one particular behavior rather than a group of similar behaviors. For example, the item "Does this child continually seek attention, as evidenced by such behaviors as speaking out of turn and making unnecessary noises?" was divided into two items. In addition, several items were added to the scale. The final scale consisted of 22 items, and each item was rated by the teacher on a 5-point scale ranging from always to never.

The items in the scale were categorized according to their expected relationship with the four types of dependency described in the sociometric behavior assessment. However, because of a lack of high intercorrelations among the items composing each grouping (especially groupings 1 and 4), the items were analyzed separately rather than grouped.

Empathy. A modification of the Feshbach and Roe Affective Situation Test for Empathy (Feshbach \& Roe, 1968) was used. The original measure consisted of eight slide sequences-two for each of the four emotions of happiness, sadness, fear, and anger-with short verbal stories. Separate slide sequences are used for boys and girls since these investigators have found that each sex is most empathic toward members of the same sex.

In the present study the same slides were used, but the accompanying verbalizations were expanded and, to some extent, changed since the children were older than those for whom the measure was originally designed. Essentially, the verbalizations tell what is happening in each slide without describing the emotional state of the characters in the stories. For example, the verbalizations for one of the fear stories for girls is as follows: (Slide 1) Lucy and her family are visiting her grandparents, who live in the country. Lucy decides to go for a walk while everybody else talks. (Slide 2) Lucy sees some trees and bushes and decides that they would be fun to explore. She walks for a while looking at all of the plants and rocks. Suddenly she realizes that she is lost. (Slide 3) Lucy decides to keep walking, hoping that she will find the right path. But there are more trees all the time. No matter which way she turns she seems to be right in the middle of the forest.

For empathy to be scored, the child was required to give the appropriate specific emotion when asked, "How do you feel?" or "How does 
this story make you feel?" Care was taken to equate the number of words used in the stories across emotions. For the two stories for each emotion the total number of words is 200 . In addition, the verbal presentation for each story was taped to ensure that the verbal intonation of the stories would remain constant across the sample. Early pretesting gave some indication that the intensity of emotion in the voice of the experimenter could affect the intensity of the child's empathic response.

The above empathic measure merely assesses the correctness of the child's empathic response without taking into account the intensity of this response. As an initial attempt to measure the intensity of the response, after each story the child was asked to rate how strongly he felt his stated emotion using a lap-sized wooden rating scale. In general, this empathic intensity measure was not significantly related to the measures of dependency and sharing, so this measure will not be included in the latter sections of this paper.

Sharing. At the end of each of two individual sessions, each child was allowed to choose 8 out of 20 items (worth approximately a nickel each) from a bowl. Of the 20 items in the bowl, 10 were different kinds of items with two of each item. Seven of the 10 items were varieties of candy, 1 was a box of raisins, and the last 2 were a colored pencil and a pen.

After the child had chosen his eight items, he was then given the option of donating all, some, or none to a fictitious group called "Give and Share," who give things to "kids whose parents don't have much money to buy them things." The child donated by putting however many items he wanted in a clear plastic jar with an opening in the top of a tight-fitting lid. Twenty-seven items were always in the jar at the time the child was given the opportunity to share.

For the visible sharing measure, the experimenter was present while the child chose his items and decided whether or not to share any of his items. During the invisible sharing measure, the experimenter left the room immediately following giving the instructions to the child. Because of the 27 items in the plastic jar, it was assumed that the child would believe that his contribution was strictly anonymous.

Incidentally, the child had the opportunity to steal candy as well as donate in the invisible sharing situation. If a child stole candy, his sharing score was a negative number, the number of items that were stolen. Eight of the 66 children in the study stole candy in this situation.

The data in this section were scored not only for visible and invisible sharing (number of items donated in each situation) but also for total sharing and difference in sharing. The total sharing score was simply the number of items given in the visible sharing situation added to the number 
of items given in the invisible sharing situation. Similarly, the difference score was the number of items donated in the visible sharing situation minus the number of items donated in the invisible condition.

\section{Procedure}

Each child was seen individually by the experimenter on two different occasions during school time. Each of the two sessions lasted approximately a half hour. During the first session the empathy task was administered followed by a sharing measure. The second session consisted of the administration of the Children's Social Desirability Questionnaire followed by the sociometric behavioral assessment and then finally the last sharing measure.

The visible and invisible sharing measures were administered alternatively so that half the children received the visible sharing task the first time and the invisible sharing measure during the second session. For the rest of the children the procedure was reversed. Care was also taken to balance the administration of this measure for the sex of the child.

\section{RESULTS}

\section{Sex Differences}

$T$ tests were performed to examine the data for sex differences on each of the measures. As can be seen from Table I, boys and girls did not score significantly differently on either the empathy or sharing measures. However, there were significant sex differences on several of the dependency measures, with girls scoring higher in social desirability (the need for approval measure), Peer Rating 1, designed to measure the child with high dependency needs but who fears rejection, and Peer Rating 3, designed to measure moderate dependency. Boys, on the other hand, scored higher than girls on Peer Rating 2, the negative attention-seeking measure.

Similarly, when the items of the teacher rating scale were examined, boys tended to be rated higher in the negative attention-seeking behaviors, while girls were rated as being more cooperative and striving to please the teacher (Table II).

In addition, the interrelationships among the measures of dependency, empathy, and sharing were examined separately by sex. Since, in general, rather different patterns emerged for boys and girls, the interrelationships among these variables will be described separately by sex. 
Table 1. Sex Differences on the Dependency, Empathy, and Sharing Measures

\begin{tabular}{|c|c|c|c|}
\hline Measure & $\begin{array}{c}\text { Mean } \\
\text { for girls }\end{array}$ & $\begin{array}{c}\text { Mean } \\
\text { for boys }\end{array}$ & $t$ \\
\hline $\begin{array}{l}\text { Social } \\
\quad \text { desirability }\end{array}$ & 20.26 & 15.95 & $1,97^{a}$ \\
\hline $\begin{array}{l}\text { Peer } \\
\text { rating } 1\end{array}$ & 19.91 & 13.19 & $3.52 b$ \\
\hline $\begin{array}{l}\text { Peer } \\
\text { rating } 2\end{array}$ & 11.13 & 18.41 & $-4.12^{b}$ \\
\hline $\begin{array}{l}\text { Peer } \\
\text { rating } 3\end{array}$ & 18.72 & 14.08 & $2.43 a$ \\
\hline $\begin{array}{l}\text { Peer } \\
\text { rating } 4\end{array}$ & 14.06 & 17.44 & -1.66 \\
\hline Empathy & 6.41 & 6.11 & .96 \\
\hline $\begin{array}{l}\text { Visible } \\
\text { sharing }\end{array}$ & 1.52 & 1.26 & .88 \\
\hline $\begin{array}{l}\text { Invisible } \\
\text { sharing }\end{array}$ & .59 & .57 & .07 \\
\hline $\begin{array}{l}\text { Total } \\
\text { sharing }\end{array}$ & 2.11 & 1.84 & .46 \\
\hline $\begin{array}{l}\text { Difference } \\
\text { in sharing }\end{array}$ & .93 & .70 & .65 \\
\hline
\end{tabular}

Dependency and Empathy

Product-moment correlations between the empathy measure and the dependency measures are given in Table III. For girls neither social desirability nor the peer ratings were significantly correlated with empathy. For boys social desirability was significantly positively correlated with empathy.

This correlation alone, though, provides no evidence regarding the proposed curvilinear relationship between dependency and empathy. To test the proposed curvilinear model, regressions were performed comparing a linear model to a curvilinear model $\left(Y=A+B X+C X^{2}+e\right.$, where $X$ equals social desirability scores, $Y$ equals empathy scores, $A, B$, and $C$ are constants, and $e$ is the error variance). For boys, but not for girls, the reduction in variance was significant at the .05 level from the linear model to the curvilinear model. Figure 1 gives the values predicted by the curvilinear model for boys along with the confidence intervals for the actual values of empathy at the indicated levels of social desirability. 
Table II. Teacher Rating Scale: Significance Sex Differences

\begin{tabular}{|c|c|c|}
\hline Item & $\begin{array}{l}\text { Direction of } \\
\text { difference }\end{array}$ & $\begin{array}{l}\text { Attained } \\
\text { significance }\end{array}$ \\
\hline $\begin{array}{l}\text { Does this child frequently pout } \\
\text { and whine when upset? }\end{array}$ & Boys $>$ Girls & .06 \\
\hline $\begin{array}{l}\text { When this child is scolded or } \\
\text { criticized, does he become very } \\
\text { aggressive? }\end{array}$ & Boys $>$ Girls & .02 \\
\hline $\begin{array}{l}\text { Does this child publicly brag } \\
\text { of boast about his exploits? }\end{array}$ & Boys $>$ Girls & .06 \\
\hline $\begin{array}{c}\text { Does this child attempt to bully } \\
\text { or dominate other children? }\end{array}$ & Boys $>$ Girls & .07 \\
\hline $\begin{array}{l}\text { Does this child seek attention } \\
\text { by speaking out of turn? }\end{array}$ & Boys $>$ Girls & .01 \\
\hline $\begin{array}{l}\text { Does this child seek attention } \\
\text { by making unnecessary noises? }\end{array}$ & Boys $>$ Girls & .01 \\
\hline $\begin{array}{l}\text { Does this child cooperate in } \\
\text { class? }\end{array}$ & Boys $<$ Girls & .01 \\
\hline $\begin{array}{l}\text { Does this child become involved } \\
\text { in some interest or hobby of } \\
\text { his own, preferring to play by } \\
\text { himself? }\end{array}$ & Boys $>$ Girls & .06 \\
\hline $\begin{array}{l}\text { Does this child strive to please } \\
\text { the teacher? }\end{array}$ & Boys $<$ Girls & .01 \\
\hline
\end{tabular}

Of 22 teacher rating items correlated with the measure of empathy, only one was at the .10 level for boys while a different item was correlated for girls. Since two out of 22 would be expected to be correlated at the .10 level purely by chance, little importance can be attached to these correlations.

\section{Dependency and Sharing}

Table IV contains product-moment correlation coefficients between the sharing and dependency measures. For girls the only correlations that were significant were the positive correlation between Peer Rating 3 and invisible sharing and the negative correlation between Peer Rating 3 and difference in sharing. For boys social desirability was negatively related to invisible sharing and positively related to difference in sharing, and Peer Rating 1 was related negatively to both visible and total sharing.

To test the hypothesis that social desirability might be related in a curvilinear manner to invisible sharing, regressions were performed comparing a linear model to a curvilinear model $\left(Y=A+B X+C X^{2}+e\right.$, 


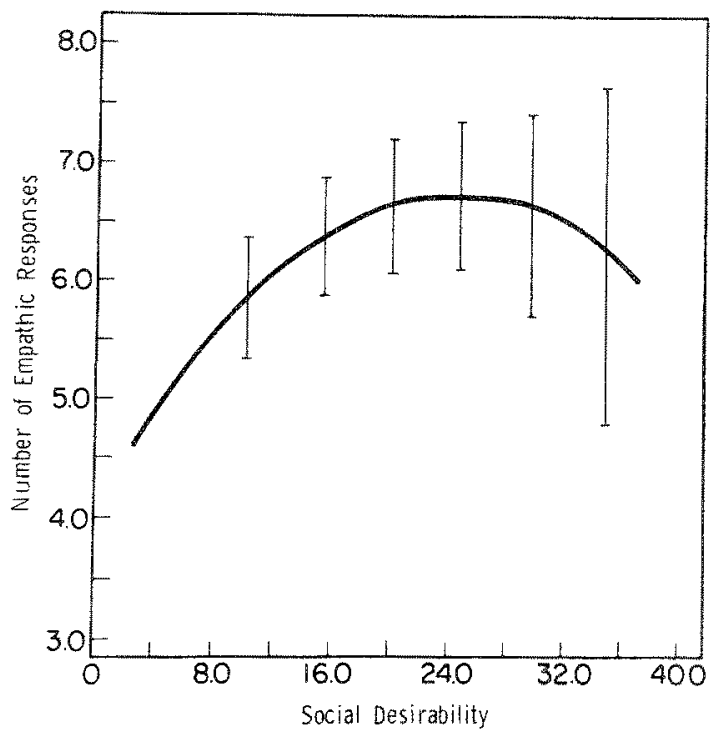

Fig. 1. Predicted curve for boys only from curvilinear regression of number of empathic responses against social desirability and .90 confidence intervals for number of empathic responses at specific levels of social desirability.

where $X$ equals social desirability, $Y$ equals invisible sharing, $A, B$, and $C$ are constants, and $e$ is the error variance). For boys, but not for girls, the reduction in variance from the linear to the curvilinear model was significant at the .01 level. Figure 2 gives the values predicted by the curvilinear model for boys along with the confidence intervals for the actual values of invisible sharing at the indicated levels of social desirability.

As can be seen from Table V, a number of the 22 teacher rating items were significantly related to the sharing variables. Across both situations girls, and to some extent boys, who gave tended to be rated as being selfconfident and assured.

Table III. Correlations between Empathy and the Dependency Measures

\begin{tabular}{lccccc}
\hline & $\begin{array}{c}\text { Children's } \\
\text { social desir- } \\
\text { ability scale }\end{array}$ & $\begin{array}{c}\text { Peer } \\
\text { rating 1 }\end{array}$ & $\begin{array}{c}\text { Peer } \\
\text { rating 2 }\end{array}$ & $\begin{array}{c}\text { Peer } \\
\text { rating 3 }\end{array}$ & $\begin{array}{c}\text { Peer } \\
\text { rating 4 }\end{array}$ \\
\hline Girls & .12 & .21 &.- .11 & .26 & .29 \\
Boys & $.39^{a}$ & .13 & -.20 & -.01 & -.08 \\
\hline$a_{p<}<.05$. & & & & \\
\end{tabular}


Table IV. Correlations between Dependency and Sharing Measures

\begin{tabular}{|c|c|c|c|c|c|c|c|c|}
\hline & \multicolumn{2}{|c|}{$\begin{array}{l}\text { Visible } \\
\text { sharing }\end{array}$} & \multicolumn{2}{|c|}{$\begin{array}{l}\text { Invisible } \\
\text { sharing }\end{array}$} & \multicolumn{2}{|c|}{$\begin{array}{c}\text { Total } \\
\text { sharing }\end{array}$} & \multicolumn{2}{|c|}{$\begin{array}{c}\text { Difference } \\
\text { in sharing }\end{array}$} \\
\hline & Girls & Boys & Girls & Boys & Girls & Boys & Girls & Boys \\
\hline $\begin{array}{l}\text { Children's } \\
\text { social } \\
\text { desirability } \\
\text { scale }\end{array}$ & -.16 & .02 & -.05 & $-.39 b$ & -.12 & -.26 & -.11 & $.43^{c}$ \\
\hline $\begin{array}{l}\text { Peer } \\
\text { rating } 1\end{array}$ & .11 & $-.37 b$ & .28 & -.16 & .23 & $-.29^{a}$ & -.20 & -.11 \\
\hline $\begin{array}{l}\text { Peer } \\
\text { rating } 2\end{array}$ & -.05 & .10 & -.15 & .21 & -.12 & .20 & .13 & -.13 \\
\hline $\begin{array}{l}\text { Peer } \\
\text { rating } 3\end{array}$ & .09 & .14 & $.41^{b}$ & .08 & .29 & .12 & $-.37^{a}$ & .01 \\
\hline $\begin{array}{l}\text { Peer } \\
\quad \text { rating } 4\end{array}$ & .16 & .19 & .23 & .21 & .22 & .24 & -.10 & -.08 \\
\hline
\end{tabular}

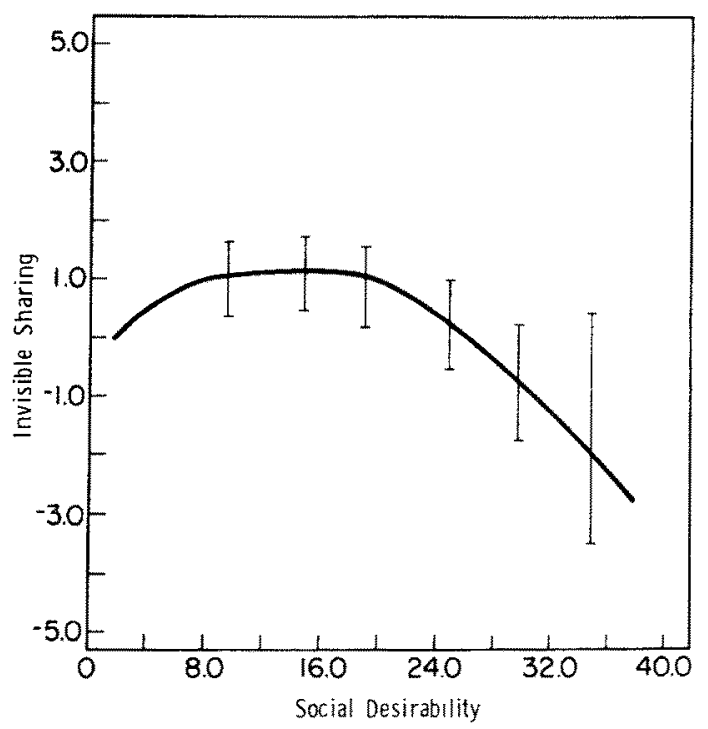

Fig. 2. Predicted curve for boys only from curvilinear regression of invisible sharing against social desirability and .90 confidence intervals for invisible sharing at specific levels of social desirability. 


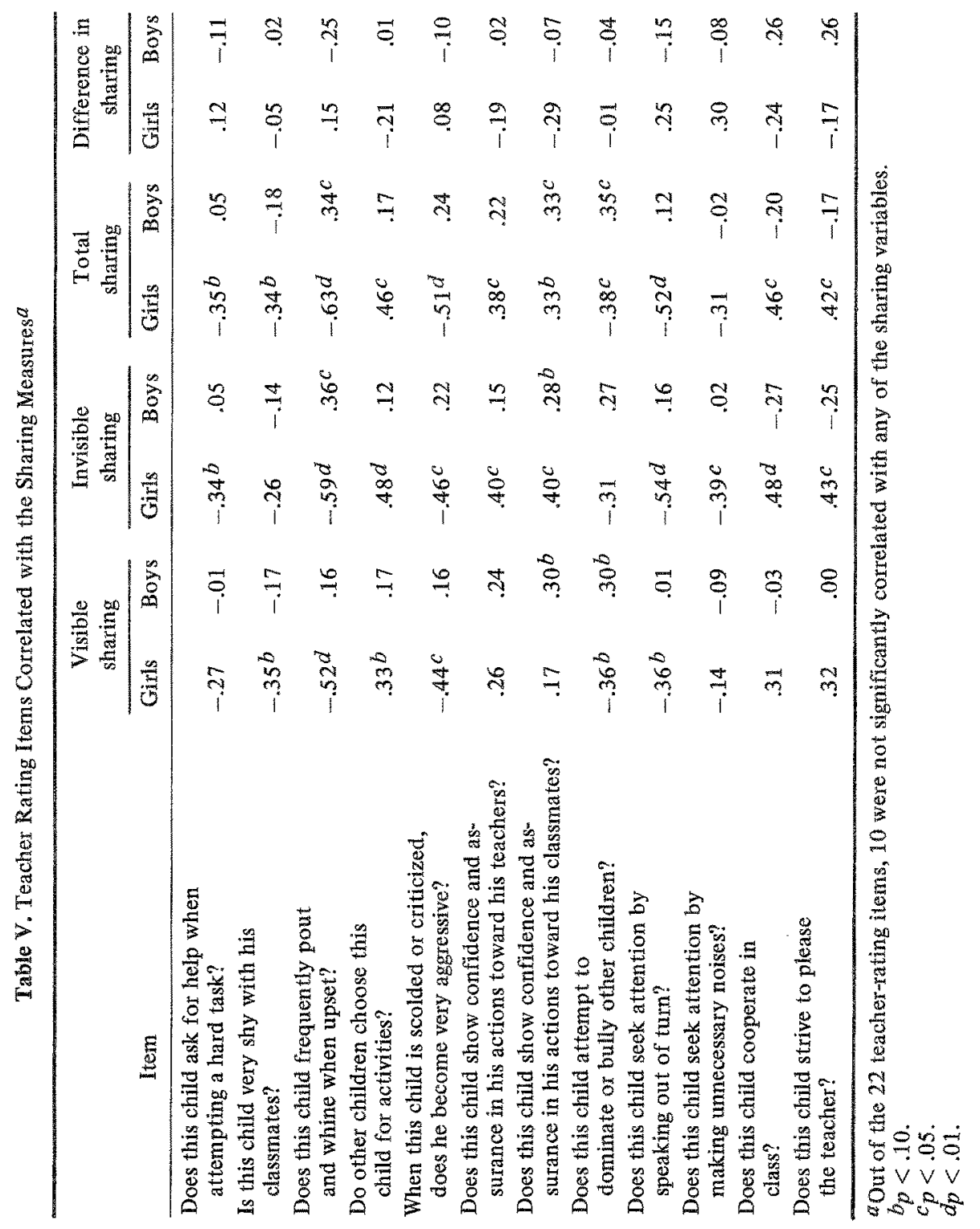


Table VI. Correlations between Empathy and Sharing Measures

\begin{tabular}{ccccc}
\hline Sex & $\begin{array}{c}\text { Visible } \\
\text { sharing }\end{array}$ & $\begin{array}{c}\text { Invisible } \\
\text { sharing }\end{array}$ & $\begin{array}{c}\text { Total } \\
\text { sharing }\end{array}$ & $\begin{array}{c}\text { Difference in } \\
\text { sharing }\end{array}$ \\
\hline Girls & $.35^{a}$ & .32 & $.38^{b}$ & -.02 \\
Boys & .02 & $-.30^{a}$ & -.19 & $.34 b$ \\
\hline
\end{tabular}

$a_{p}<.10$

$b_{p}<.05$.

\section{Empathy and Sharing}

Pearson product-moment correlation coefficients are given for the empathy and sharing variables in Table VI. For girls empathy was correlated with both visible sharing (at the .10 level of significance) and total sharing (at the .05 level of significance). The partial correlation between empathy and visible sharing, after controlling for either social desirability ( $r$ $=.34)$ or Peer Rating $1(r=.34)$, was still significant at the 10 level. Although the correlation with invisible sharing was only slightly lower $(r=$ .32), it was not significant, partially because of the small number of girls in the sample. For boys empathy was negatively correlated with invisible sharing and positively correlated with difference in sharing.

Correlations for boys and girls were converted to Fisher's $z$ scores to see if the correlations between empathy and sharing were significantly different for boys and girls. The difference in Fisher's $z$ scores for the correlations are as follows: -.34 (significant at the .20 level) for empathy and visible sharing, -.64 (significant at the .01 level) for empathy and invisible sharing, -.59 (significant at the .05 level) for empathy and total sharing, and .37 (significant at the .20 level) for empathy and difference in sharing. Thus for boys and girls the patterns between empathy and the sharing variables were very different.

\section{DISCUSSION}

Some support was found for the hypotheses presented at the beginning of this paper but without the consistency that could have been desired. Moreover, as discussed below, different correlations emerged for each sex.

For girls some support was found for the hypothesis that empathy is positively related to sharing. Correlations ranging from .32 to .38 were found between empathy and visible, invisible, and total sharing. Also, as predicted, moderate dependency may be related to invisible sharing in girls. 
Peer Rating 3, designed to identify the child who is moderate in dependency and who is not afraid to approach others, was positively related to invisible sharing $(r=.41)$ in girls. Also, girls who gave more in the invisible sharing condition tended to be more cooperative and desirous of pleasing their teacher (as indicated by the teacher rating scale) and lower in the negative attention-seeking behaviors. These correlations support the hypothesis that moderate dependency is related to invisible sharing in girls.

It was originally hypothesized, however, that moderate dependency would be correlated with invisible sharing because of the mediating role of empathy. However, little support was found for this hypothesized role of empathy since the correlation ( $r=.26)$ between empathy and Peer Rating 3 was not significant. Moreover, when a partial correlation coefficient was computed between Peer Rating 3 and invisible sharing, controlling for number of empathic responses, the partial correlation coefficient between these two variables $(r=.36)$ was still significant at the .10 level. In this sample, then, moderate dependency, as assessed by Peer Rating 3, was positively related to invisible sharing, even after possible effects of empathy were eliminated.

An alternative explanation for the above correlations would be as follows: The girl who is moderate in dependency may be fulfilling the sexrole expectations of parents and teachers. In other words, moderate dependency strivings may be positively reinforced in the girl's daily experiences. Hence, the girl who is moderate in dependency because her behavior is congruent with societal sex-role expectations may be higher in self-esteem and more confident in her relationships with peers and teachers.

Consistent with this interpretation are the relationships between Peer Rating 3 and the teacher ratings, as is discussed elsewhere (Miller, 1976). Girls scoring high on Peer Rating 3 were rated as being self-confident and assured in dealings with both peers and teachers and as having a sense of self-worth and self-esteem. In line with the "happy mood" and "warm glow of success" research (Berkowitz \& Conner, 1966; Isen, 1970; Isen, Horn, \& Rosenhan, 1973; Moore, Underwood, \& Rosenhan, 1973), these girls may be more generous because in general they are happier and more successful than their peers in their lives both in and out of the classroom.

On the other hand, dependency, especially high dependency, may be less socially acceptable in the male. Attempts to satisfy dependency needs by boys may be met with frustration. Past research has shown that boys scoring high in social desirability have high need for approval but do not approach others because of expectations of rejection (Crandall, 1966). For boys, as compared to girls, these expectations of rejection may be particularly realistic. This may explain why social desirability was negatively correlated with invisible sharing for boys. Perhaps because of past experi- 
ences of rejection, these boys were lower in self-esteem (as has been found with previous research with the social desirability measure) and hence more unhappy, had experienced fewer successes in life, and therefore were less likely to be generous with others.

On the basis of this interpretation, how can the positive correlation for boys between social desirability and empathy be explained? Perhaps boys who were higher in social desirability gave more empathic responses in an attempt to win approval from the investigator. That is, though in general boys scoring high in social desirability do not make active bids for attention because of fear of rejection, perhaps this situation was sufficiently structured so that the boys had to give some response, and therefore gave the response that they thought was desired by the investigator.

Alternatively, perhaps the boys who were higher in social desirability were actually more empathic in their reactions to the plights of others as depicted in the stories. Perhaps experiences of rejection, for example, increased their ability to empathize with the boy in one story who was new in town and without friends. If this explanation of the findings is accepted, then how can one explain the comparative lack of empathy by these boys for the poor children in the sharing situations? Two explanations are possible. Perhaps the candy and other items meant more to the boys who were high in social desirability (and hence empathy), and they were thus more reluctant to part with them. Thus, though they were empathic, sharing did not result.

On the other hand, perhaps this sharing task was not capable of maximizing empathy in the boys. Little was said to describe who would benefit from the sharing. "Kids whose parents don't have much money" may be too vague a description to successfully arouse empathy in the boys. Also, poor children are probably less likely to go without candy than without more expensive clothes and toys.

\section{CONCLUSIONS}

The present study has attempted to delineate the relationships among several personality variables within a framework of specific hypotheses. It should be emphasized that this research has been preliminary. Further research is needed to more precisely define the relationships among these variables.

As is discussed elsewhere (Miller, 1976), further differentiation of the dependency measures is needed. Also, the empathy measure used in this study was not entirely satisfactory, and continued revisions of this measure are needed. Feshbach and her associates have used the same set of eight 
stories in all of their empathy research. Results using these stories need to be compared with results using completely different stories for the four emotions of happiness, sadness, fear, and anger. Also, more variance is needed in the empathy scores. Although most of the fourth-graders in this study gave an incorrect empathic response to at least one story, 10 of the children gave the correct empathic response on all eight stories.

The empathy measure should include some assessment of the intensity of the emotion experienced by the child in response to the story. An attempt was made in this study to measure this aspect of empathy, but further work needs to be done in this line.

The situational measure of sharing used here was not completely satisfactory either. First, there was not sufficient variability in the number of items donated in any of the situations. This could be changed by giving the child more items that were each worth less. However, ensuring that the items were equally attractive to all of the children might be more difficult if this change were made.

In the analyses here, stealing was treated as being on the opposite end of a continuum with sharing. If this assumption is incorrect, the 8 out of 66 children who stole candy in the invisible sharing condition may have adversely affected the results.

Finally, any findings regarding sharing need to be validated over a wide range of situations. As was pointed out by Gergen, Gergen, and Meter (1972), the correlates of prosocial behavior vary widely, depending upon the specific prosocial situation in question.

Neither the importance nor the complexity of the problems involved in doing such research should be underestimated. Very little research has been done in the past to investigate the relationships among these character constructs. As mentioned previously, empathy has been regarded as an important motivating factor for prosocial behavior. Yet more research needs to be conducted to test this hypothesis.

Research relating dependency and empathy is, to this author's knowledge, nonexistent in the literature. That further research into this area may be worthwhile is indicated by the positive correlation found between social desirability and empathy for boys.

Similarly, the possible positive relationship between moderate dependency and invisible sharing for girls is a finding that is new and worthy of further examination.

The curvilinear analysis of the interrelationships among the variables is a new dimension of the research in this area, also. For example, as was found for boys in the present study, Staub and Sherk (1970) found a negative relationship between social desirability and candy sharing. The data in this study, unlike those in the Staub and Sherk study, were analyzed accord- 
ing to a curvilinear model. This model was found to be a significantly better predictor of invisible sharing for boys than a linear model, indicating that at the lower end of the social desirability scores the negative relationship between social desirability and invisible sharing tended to be reversed. The curvilinear model was also found to be significantly better than a linear model for relating social desirability and empathy. Although social desirability was significantly positively related to empathy for boys, as indicated by predictions from a curvilinear regression, at the upper end of the social desirability scores, the positive trend between social desirability and empathy tended to be reversed.

The results from this study are important for one more reason. Frequently, if boys and girls score approximately equally on a measure, the data are analyzed by lumping the scores together in the analyses. Although boys and girls did not significantly differ in their scores on the empathy and sharing measures, the relationships between these variables were nevertheless very different for each sex. In other words, just because no significant sex difference is found on a measure, it is presumptuous to assume that the underlying motivations resulting in those scores are the same for boys and girls.

In conclusion, inconsistent support was found for the original hypotheses of the study. However, the correlates that were found among the variables are interesting and suggestive of possible complex relationships among dependency, empathy, and sharing.

\section{REFERENCES}

Aronfreed, J., \& Paskal, V. Altruism, empathy, and the conditioning of positive affect. Unpublished manuscript, University of Pennsylvania, 1965.

Berkowitz, L., \& Conner, W. H. Success, failure and social responsibility. Journal of Personality and Social Psychology, 1966, 4, 664-669.

Coopersmith, S. The antecedents of self-esteem. San Francisco: Freeman, 1967.

Crandall, V. Personality characteristics and social achievement behaviors associated with children's social desirability response tendencies. Journal of Personality and Social Psychology, 1966, 4, 447-486.

Crandall, V. C., Crandall, V. J., \& Katkovsky, W. A children's social desirability questionnaire. Journal of Consulting Psychology, 1965, 29, 27-36.

Crowne, D., \& Marlowe, D. The approval motive: Studies in evaluative dependence. New York: Wiley, 1964.

Gergen, K. J., Gergen, M. M., \& Meter, K. Individual otientations to prosocial behavior. Journal of Social Issues, 1972, 28, 105-130.

Feshbach, N. D., \& Roe, K. Empathy in six and seven year olds. Child Development, 1968, $39,133-145$.

Heathers, G. Acquiring dependence and independence: A theoretical orientation. Journal of Genetic Psychology, 1955, 87, 277-291.

Hoffman, M. L. Developmental synthesis of affect and cognition and its implications for altruistic motivation. Developmental Psychology, 1975, 11, 607-622. 
Isen, A. M. Success, failure, and reaction to others: The warm glow of success. Journal of Personality and Social Psychology, 1970, 15, 294-301.

Isen, A. M., Horn, N., \& Rosenhan, D. L. Effects of success and failure on children's generosity. Journal of Personality and Social Psychology, 1973, 27, 239-247.

Krebs, D. L. Empathy and altruism. Journal of Personality and Social Psychology, 1975, 32, 1134-1146.

Martin, B. Parent-child relations. In F. D. Horowitz (Ed.), Review of child development research (Vol, 4). Chicago: University of Chicago Press, 1975.

Martin, P. L. Empathy and observation in the modeling of altruistic behavior. Dissertation Abstracts International, 1972, 32, 4108.

Miler, S. M. Dependency, empathy, and altruism: A preliminary study of proposed relationships. Unpublished doctoral dissertation, University of Michigan, Ann Arbor, 1976.

Moore, S. S., Underwood, B., \& Rosenhan, D. L. Affect and altruism. Developmental Psychology, 1973,8,99-104.

Staub, E., \& Sherk, L. Need for approval, children's sharing behavior, and reciprocity in sharing. Child Development, 1970, 41, 243-252. 